\title{
Historiografía de las relaciones argentino-brasileñas
}

Edmundo A. Heredia

CONICET. Argentina

Se presenta una lista de libros, opúsculos, folletos y artículos referidos a la historia de las relaciones entre Argentina y Brasil, comprendiendo publicaciones antiguas y recientes. La intención ha sido mostrar un repertorio, relativamente amplio, de la producción historiográfica sobre el tema, de modo que pueda observarse la evolución de estos estudios en el tiempo y los temas que en su transcurso han provocado la atención de los historiadores. Se ha hecho una división cronológica teniendo en cuenta los hitos más significativos de la historia de estas relaciones. La lista es precedida por una presentación en la que se señalan las características generales de estas relaciones, como así también las tendencias de la historiografía, ubicando ambas en el contexto general de la historia de las relaciones interamericanas y marcando así sus peculiaridades y rasgos distintivos.

\section{Contexto histórico}

Las relaciones de tipo bilateral son las que han provocado mayor atención en la historiografía de las relaciones interamericanas. Si bien, en general, esas relaciones pertenecen a la época contemporánea —más precisamente desde la formación de los nuevos Estados nacionales-, hay unas que se destacan del resto debido a su mayor longitud temporal, y en tanto reflejan en la contemporaneidad cuestiones internacionales planteadas durante la época colonial. Ellas son las que corresponden a los confines del antiguo imperio español, septentrional y meridional, contiguos a las posesiones territoriales de Gran Bretaña y de Portugal.

Las relaciones que han mantenido recíprocamente México y los Estados Unidos y las de Brasil con las naciones platenses - y de éstas especialmente Argentina - presentan, así, una particularidad que las distingue de las que ha sostenido el resto de las naciones americanas entre sí. Las relaciones internacionales entre estos pares de naciones deben remontarse, por tanto, al período colonial, y vincularse con las disputas entre ambas metrópolis (Gran Bretaña-España y Portugal-España) ventiladas tanto en escenarios europeos como en los americanos. Los conflictos, acuerdos o alianzas que establecieron para atender cuestiones netamente europeas repercutieron en sus colonias americanas, y a menudo esas colonias fueron piezas importantes de las negociaciones, llegando hasta a ser 
objeto de venta o canje en función de la solución de problemas propios del continente europeo.

Las relaciones entre Brasil y Argentina se distinguen aún de todas las demás porque ellas nacen prácticamente con el arribo inicial a la América del Sur de los súbditos de las Coronas española y portuguesa. El conflicto radicaba entonces exclusivamente en los límites territoriales y marítimos que correspondían a una y a otra, y dio lugar a arduas discusiones y a numerosos tratados, todos ellos cuestionados a lo largo de la historia. Se trataba en los primeros tiempos de planteamientos más bien teóricos y abstractos, pues mucho tardaron los conquistadores y colonizadores portuguesas y españoles hasta encontrarse frente a frente y hallar así motivos reales de controversias, en estas infinitudes de espacios que fueron descubriendo.

Puede entonces afirmarse que las relaciones entre Argentina y Brasil son las más antiguas de América. Por eso las historias que se escriben sobre estas relaciones recurren todavía a aquellos orígenes para encontrar mejores explicaciones, y se remontan hasta las Bulas Alejandrinas y el Tratado de Tordesillas, desde 1493, arreglos con los cuales las dos naciones iniciaron esta larga y difícil trayectoria por dirimir los límites de sus posesiones en América.

Hay una segunda condición que las caracteriza y distingue, y explica también su antigüedad y persistencia, originada en el hecho de que la contigüidad de sus posesiones americanas es una característica que se presenta también en los territorios nacionales de la Península Ibérica. Por tal motivo, a menudo los problemas suscitados por la vecindad europea repercutieron sensiblemente en los respectivos dominios americanos, y las disputas limítrofes metropolitanas encontraron argumentos y principios de solución en arreglos también limítrofes pero de territorios coloniales.

Hay todavía una tercera singularidad, y es la que se refiere a las cuestiones dinásticas y monárquicas. Las familias reales de Braganza y de Borbón sostuvieron entre sí matrimonios y guerras; como es perfectamente humano, algunos matrimonios terminaron en guerra y algunas guerras terminaron en matrimonio. No fue ajeno a todo esto el ámbito colonial; baste recordar que en el momento de la emancipación rioplatense se pensó coronar en Buenos Aires a una princesa Borbón, hermana del rey español cautivo entonces de Napoleón y esposa mal avenida del príncipe Braganza instalado en Río de Janeiro. Las gestiones contaron con el apoyo de unos y la repulsa de otros sectores palaciegos lusitanos, y lo mismo ocurrió en sectores dirigentes rioplatenses. De tal manera, algunos de los fundadores de 
la nacionalidad argentina heredaron la inveterada práctica dinástica de sus viejas metrópolis europeas, inaugurando así las relaciones independientes con una fuerte tendencia tradicionalista.

$\mathrm{Al}$ ingresar en el conocimiento de esta historiografía debe tenerse en cuenta también que las relaciones entre Argentina y Brasil, aún las restringidas a la bilateralidad, merecen ser consideradas dentro de un ámbito más amplio, en razón de ser las dos naciones mayores —al menos en superficie y población - dentro de la gran cuenca del Plata a la que pertenecen asimismo Bolivia, Paraguay y Uruguay. Las relaciones entre los dos países, por tanto, han rozado siempre de algún modo las cuestiones que involucraban a los otros tres. Precisamente estas tres naciones habían formado parte del Virreinato del Río de la Plata, y durante muchos años de vida independiente siguieron siendo partes significativas en las vicisitudes de las relaciones entre las dos primeras. Baste recordar que durante el período de la Confederación rosista, hasta 1852 , este gobierno no reconoció la independencia del Paraguay, al que consideraba una provincia argentina, y que aún después de la fundación de la república uruguaya, en 1828, el gobierno y la dirigencia argentinos mantuvieron activa ingerencia en la vida política interna de ese país. Por eso las relaciones bilaterales de Argentina y Brasil se encuadran en un ámbito mayor que comprende las relaciones interregionales de la cuenca platense.

Las dos guerras en las que fueron co-protagonistas las dos naciones en el siglo XIX han ocupado preferente atención de los estudiosos. Se enfrentaron en la primera de esas guerras, por la posesión de la Banda Oriental; el resultado, aunque favoreció el nacimiento de una nueva nación, no zanjó sin embargo las diferencias de siglos, de modo que en los años siguientes el tono predominante continuó siendo el del recelo y el conflicto permanentes. En cambio fueron aliadas en la segunda contienda, destinada a poner término al poder de López en el Paraguay, y ese acuerdo revela también una tendencia a reconocerse recíprocamente como líderes de la región y a no admitir en consecuencia un tercer oponente. Siguieron así una línea ya transitada por el Directorio argentino cuando consintió la entrada brasileña a la Banda Oriental para apagar el fuego del federalismo de Artigas. Esta doble y complicada política de hegemonía en la región, frente a vecinos alternativamente rivales o amigos, tradicionalmente más débiles pero que oponían esporádicos intentos por alcanzar mejores posiciones relativas, ha provocado interpretaciones diversas y opuestas en los historiadores de ambos países. 
Otra gran cuestión siempre latente en las relaciones ha sido la de la confrontación de los sistemas de gobierno, durante el tiempo en el que en el Brasil se mantuvo la monarquía. Los gobiernos argentinos usaron esta situación como recurso para estimular en las repúblicas hispanoamericanas las prevenciones contra los supuestos peligros que el régimen implicaba para la estabilidad de sus propios sistemas republicanos, generalizados en el continente. El hecho de que predominaran aquí las repúblicas y en Europa las monarquías era presentado como eficaz y simple argumento para sostener que la libertad y la emancipación se afirmaban en las repúblicas, en tanto las coronas reales perpetuaban el sometimiento y el vasallaje. Como contrapartida, el Imperio apelaba al orden superior que imponían sus instituciones por el respeto que inspiraba su emperador, oponiéndolo al permanente estado de desorden y a veces de caos en que quedaban sumidas las repúblicas, tan difíciles de gobernar. Obviamente, cuando se registran los momentos más cálidos de los conflictos, el contraste entre monarquía y república aparece con mayor intensidad y es entonces cuando la historiografía lo recoge, en tanto que no ha merecido mayormente una atención separada desde el punto de vista de la historia de las instituciones políticas, salvo algunos estudios de brasileños sobre las dificultades de convivencia y vecindad entre una monarquía y una veintena de repúblicas.

En fin, las relaciones entre Brasil y Argentina han sido ricas, complejas, conflictivas. Ofrecen, por tanto, temas inagotables para los estudiosos que, en efecto, han producido un nutrido y valioso repertorio.

\section{Notas sobre la historiografía}

En 1982 María Regina Soares de Lima y Gerson Moura publicaron "Brasil-Argentina: Fontes Bibliográficas", en Revista Interamericana de Bibliografía (vol. XXXII, n. ${ }^{3}$ 3-4, págs. 295-321. Washington, 1982). Dividieron esa nómina en dos grupos, uno referido a obras históricas y el otro a trabajos lindantes con la actualidad. Obviamente, se trata de una lista parcial; a pesar de ser más extensa, también lo es ésta que ahora presentamos. En cierta medida, la diferencia numérica se debe a que hemos podido incorporar publicaciones que no habían aparecido aún cuando estos autores hicieron su trabajo. Preferimos aquí omitir en su mayor parte las referencias bibliográficas ya aportadas por estos autores, por considerar 
innecesaria su repetición, aunque hemos exceptuado de esa omisión una docena de obras que nos parecen dignas de ser remarcadas. Entendemos que las dos listas se complementan sin superponerse; también destacamos la conveniencia de consultar las obras generales citadas por Lima y Moura para un mejor conocimiento de estas relaciones.

Con el criterio restringido a las relaciones bilaterales, la clasificación del repertorio que ahora ofrecemos obedece naturalmente a una base cronológica y la división está marcada por los hitos significativos en la historia de estas relaciones; han sido agregados, sin embargo, dos temas que merecieron atención separada de algunos autores: las relaciones económicas y las cuestiones limítrofes o fronterizas.

De tal modo, la lista tiene una primera sección para las obras que se ocupan de un tiempo largo, en ocasiones desde los mismos orígenes hasta la contemporaneidad. Es notoria en este grupo una característica que se revela a partir de la propia titulación de los trabajos y consiste en que en su mayoría se refieren a la política o acción de Brasil en Argentina, y no a la inversa, como si el primero hubiera tenido siempre el papel activo y la segunda el papel pasivo en estas relaciones. Incluso autores brasileños admiten el término "expansionismo" para caracterizar ese papel activo, aunque en algunos casos lo hacen para presentar explicaciones que encierran sutiles o rotundas justificaciones.

La segunda sección corresponde al período de la independencia, y en ella se incluyen sus prolegómenos, ya que la venida de la Corte portuguesa al Brasil, en 1808, tuvo su impacto en la situación prerrevolucionaria de Buenos Aires. Hubo en ese período dos entradas de tropas brasileñas a la Banda Oriental que conmovieron las relaciones con el gobierno argentino, la segunda con el propósito ostensible de incorporar la provincia al reino lusitano. Debe anotarse para esta época la complejidad y multiplicidad de las relaciones, pues tales ocupaciones afectaban intereses de España, de revolucionarios argentinos y de federalistas y republicanos uruguayos, además de la ingerencia de Gran Bretaña, que había puesto ya su atención sobre este sector como de interés significativo para la grandeza de su Imperio. Al considerarse las relaciones bilaterales éstas deben integrarse, en consecuencia, dentro de un conjunto múltiple de intereses e intervenciones.

La siguiente sección corresponde a la guerra entre Brasil y Argentina por la posesión de la Banda Oriental. Se trata de un breve pero intenso período, en el que se decidió la independencia uruguaya. Fue la solución de 
carácter geopolítico en que desembocaron los intentos diplomáticos y la acciones bélicas. Tratándose de un problema agudo y vital para ambas naciones, la historiografía acusa también las perspectivas nacionales agitadas en uno y otro país, evidenciando así tomas de posiciones teñidas a veces de intenso sentido nacional.

La sigue la etapa de tensiones y conflictos ahora fundamentados en los desacuerdos en cuanto al cumplimiento de la Convención Preliminar de Paz de 1828 — que obligaba a ambos gobiernos a garantizar el sostenimiento de la independencia de Uruguay-, comprensiva también de las dilaciones para la firma del Tratado definitivo de paz. El gran protagonista de este período fue Juan Manuel de Rosas, en su carácter de gobernador de Buenos Aires y encargado de las Relaciones Exteriores. La permanente intervención de la Confederación Argentina en las luchas políticas internas uruguayas constituyó la causa ostensible para el mantenimiento de los seculares recelos y desconfianzas. El partido unitario, empeñado en derrocar a Rosas, encontró en Brasil un aliado decisivo para lograr sus propósitos y la participación del Brasil en la campaña unitaria convirtió a la vida política interna de la Argentina en una cuestión propia de las relaciones internacionales. Ello ha motivado un particular tratamiento del tema por la historiografía nacional, con eclosión de pasiones que desbordan a menudo un análisis frío y mesurado. En un extremo, los autores liberales explican la acción de tropas brasileñas en territorio argentino como una empresa liberadora y civilizadora; en el otro extremo, los revisionistas acusan de claudicación y traición a los dirigentes implicados en lo que califican de conjura internacional. En este caso, al recelo permanente se une la defensa de posiciones políticas nacionales. Los autores brasileños, en tanto, pueden tratar la cuestión sin mayor carga de conciencia, pues esta vez su intervención en el Plata fue impulsada por la solicitud argentina.

Sugerentemente, el período posterior a la caída de Rosas y hasta la guerra de la Triple Alianza, de que trata la siguiente sección, ha ocupado poca atención de los historiadores. Es un período neutro, con algunos entendimientos y aproximaciones, sobre todo en el terreno de los intercambios económicos. Es como un interregno, y así parecen entenderlo los historiadores, salvo los escasos estudiosos que se han ocupado de este momento singular de las relaciones.

Para el período de la guerra de la Triple Alianza en adelante hay un nutrido repertorio historiográfico. Otra vez más, a los estudios concienzudos se agregan los alegatos que pendulan entre la acción civilizadora y el 
genocidio y en cierto modo se explica esta característica por tratarse de la mayor y más cruenta guerra habida en territorio sudamericano. Los seculares rivales se encontraron esta vez unidos contra un enemigo común, y esto ha ocasionado también una actitud singular en la historiografía: que autores brasileños se identifiquen con autores argentinos, y viceversa, coincidiendo en uno de los dos extremos del péndulo. Al fin, es plausible que al menos una vez las distancias de interpretación se acorten, pero de todos modos subsisten rotundas discrepancias, ya no exclusivamente por cuestiones de defensa de las respectivas nacionalidades.

La secuencia cronológica concluye con algunos estudios referidos al siglo XX, en donde los historiadores se encuentran con los científicos políticos de las relaciones internacionales; hemos preferido limitar las referencias a ciertos trabajos de connotaciones rigurosamente históricas, pues de otro modo hubiéramos entrado en un campo en el que predomina un enfoque proveniente de otras disciplinas sociales o humanas.

Finalmente, hemos incorporado dos secciones, referidas a cuestiones económicas y de límites. Se han colocado aquí las obras específicas sobre ambos temas, aunque ellos también están de un modo u otro presentes a lo largo de muchos estudios incluidos en otras secciones.

Por último, nos complace señalar que el número de autores brasileños mencionados es muy semejante al de los argentinos; por lo demás, la suma de los autores de las dos nacionalidades constituye la casi totalidad de la producción citada. Al menos en este aspecto la lista refleja una realidad, superando así una tendencia de la misma historiografía en cuanto a la utilización marcadamente unilateral de las fuentes bibliográficas según la nacionalidad de los autores.

\section{General}

Aragao e Frota, Luciara S. de: "Brasil y Argentina: Un enfoque histórico de la Integración". En Mundo Nuevo. Caracas, enero-marzo de 1990. Bandeira, Moniz: O expansionismo Brasileiro. O papel do Brasil na Bacia do Prata. Da colonizaçao ao Império. Rio de Janeiro, Philobiblion, 1985.

Barroso, Gustavo: O Brasil em face do Prata. Rio de Janeiro, Impr. Nacional, 1930.

Cardozo, Efraín: El Imperio del Brasil y el Río de la Plata. Buenos Aires, Librería del Plata, 1961. 
Lafuente Machaín, Ramiro: Los portugueses en Buenos Aires. Madrid, 1931.

Oneto y Viana, Carlos: La diplomacia del Brasil en el Río de la Plata. Montevideo, Claudio García, 1903.

Pinto, Antonio Pereira: Intervençoes do Brasil no Rio da Prata. Rio de Janeiro, 1871.

Pomer, León: Conflictos en la Cuenca del Plata en el Siglo XIX. Buenos Aires, Riesa, 1984.

Quesada, Vicente G.: La política del Brasil con las Repúblicas del Río de la Plata. Buenos Aires, Baccaro, 1919.

Rocha, Justiniano José da: A política do Brasil no Rio da Prata. Rio de Janeiro, Tipografía do Brasil, 1950.

Scenna, Miguel Angel: Argentina-Brasil, Cuatro Siglos de Rivalidad. Buenos Aires, La Bastilla, 1975.

Silioni, Rolando Segundo: La diplomacia Luso-Brasileña en la Cuenca del Plata. Buenos Aires, Ed. Rioplatense, 1975.

Soares, Alvaro Teixeira: Diplomacia do Império no Rio da Prata (até 1865). Rio de Janeiro, 1955.

\section{De la Colonia a la Independencia}

Abadíe Aicardi, Aníbal y Oscar Abadíe Aicardi: Portugueses y Brasileños hacia el Río de la Plata. Un informe geopolítico (1816). Recife, Pool Ed., 1977.

Azevedo, Walter Alexander de: "La misión secreta del Mariscal Curado al Río de la Plata (1808-1809)", en Boletín del Instituto de Historia Argentina y Americana, tomo II, n. ${ }^{\circ}$ 5. Buenos Aires. También en Revista do Instituto Histórico e Geográfico Brasileiro, tomo CXCII. Rio de Janeiro, julio-septiembre de 1946.

Caillet-Bois, Ricardo: "La ocupación de la Banda Oriental por los Portugueses y la mediación de las Potencias Europeas (1816-1820)", Boletín del Instituto de Historia Argentina "Dr. Emilio Ravignani", año IX, tomo IX (2. ${ }^{a}$ Serie), n. ${ }^{\circ}$ 14-15. Buenos Aires, 1967.

Cassal, Esther Suzzi: "La misión Rademaker a Buenos Aires y el Armisticio con Portugal en 1812". Anuario del Departamento de Historia, año 1, n. ${ }^{\circ} 1$. Universidad Nacional de Córdoba. Córdoba, 1963. 
Cortesao, Jaime: "O território da Colonia do Sacramento e a formaçao dos Estados Platinos”. Revista de História, año V, n. ${ }^{\circ}$ 17. Sao Paulo, enero-marzo de 1954.

Docca, Emilio Fernandes Souza: O Brasil no Prata, 1815-1828. Porto Alegre-Coimbra, 1931. También en Revista do Instituto Histórico e Geográfico do Rio Grande do Sul, año XI. Porto Alegre, 1931.

Etchepareborda, Roberto: "Entretelones del proceso Carlotino". En Historia, año II, n. ${ }^{\circ}$ 8. Buenos Aires, abril-junio de 1957.

- "Carlos José Guezzi, primer negociador diplomático ante la Junta de Mayo". Historia, año V, n. ${ }^{\circ}$ 21. Buenos Aires, octubre-diciembre de 1960.

- "Felipe Contucci y el Carlotismo". Anuario del Instituto de Investigaciones Históricas, n. ${ }^{\circ}$ 4. Universidad Nacional del Litoral, Rosario, 1960.

— "Relaciones Luso-porteñas a comienzos de 1812". Boletín de la Academia Nacional de la Historia, vol. XXXV. Buenos Aires, 1964.

— "Política Luso-rioplatense: 1810-1812". Boletín de la Academia Nacional de la Historia, año XXXVIII, n. ${ }^{\circ}$ XXXII. Buenos Aires, 1961.

— "La invasión portuguesa de 1811. Misión mediadora de Felipe Contucci”. Investigaciones y Ensayos, n. ${ }^{\circ}$ 4. Academia Nacional de la Historia. Buenos Aires, enero-junio de 1968.

- "Manuel Belgrano y los proyectos carlotinos frente al arribo del Nuevo Virrey del Río de la Plata". Investigaciones y Ensayos, n. 9. Academia Nacional de la Historia. Buenos Aires, julio-diciembre de 1970 .

- Qué fue el Carlotismo. Buenos Aires, Plus Ultra, 1972.

Fregueiro, Clemente L.: "La política lusitana y la Revolución de Mayo en el Uruguay (1808-1812)”. En Estudios Históricos sobre la Revolución de Mayo. Tomo I. Buenos Aires, 1930.

Gandía, Enrique de: "La Princesa del Brasil, la diplomacia Inglesa y el reino de Buenos Aires". Anales de la Sociedad Científica Argentina, tomo CXLIV. Buenos Aires, agosto de 1947.

Heredia, Edmundo A.: “El 'Carlotismo', los ingleses y el comercio exte-

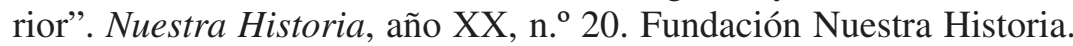
Buenos Aires, 1977. 
Loza, Emilio: "La campaña de la Banda Oriental (1810-1813)". Historia de la Nación Argentina. Academia Nacional de la Historia. vol. V, 2. ${ }^{a}$ sección. Buenos Aires, 1961.

— "La invasión Lusitana, Artigas y la defensa de la Banda Oriental". Historia de la Nación Argentina. Academia Nacional de la Historia. vol. VI. Buenos Aires, 1962.

Mille, Andrés: La Cuenca del Plata. Antecedentes para su historia (hasta 1801). Buenos Aires, 1972.

Molinari, Diego Luis: El protectorado portugués en el Virreinato del Río de la Plata. 1808. Marzo-mayo. Buenos Aires, 1922.

- "La política lusitana y el Río de la Plata. I. La alianza franco-española y el Portugal (1800-1801). II. La rivalidad hispano-portuguesa en el Río de la Plata (1777-1801)". Historia de la Nación Argentina. Academia Nacional de la Historia. Vol. V, 1. a sección. Buenos Aires, 1961.

Piccirilli, Ricardo: "Los emigrados porteños y el comisionado Manuel José García en Río de Janeiro, 1815-1816". Boletín del Instituto de Historia Argentina "Dr. Emilio Ravignani", año IX, tomo IX (2. ${ }^{a}$ serie), núms. 14-15. Buenos Aires, 1967.

- Argentinos en Río de Janeiro. 1815-1820. Buenos Aires, Ed. Pleamar, 1969.

Quesada, Vicente G.: "Diplomacia americana. El Brasil y el Río de la Plata. Negociación Rademaker. Armisticio de 1812". Nueva Revista de Buenos Aires, n. ${ }^{\circ}$ 6. Buenos Aires, 1882.

- "Diplomacia americana. El Brasil y el Río de la Plata. Negociaciones internacionales. 1808-1812". Nueva Revista de Buenos Aires, n. ${ }^{\circ} 6$. Buenos Aires, 1882.

Resnick, Enoch F.: “A Family Imbroglio: Brazil's Invasion of the Banda Oriental in 1816 and Repercussions on the Iberian Peninsula, 18161820". Revista de História, año XXVI, vol. LI, n 101. Sao Paulo, enero-marzo de 1975.

\section{Guerra de la Banda Oriental o Cisplatina}

Báez, Adolfo: Convención preliminar de paz entre el Imperio del Brasil y la República Argentina. Buenos Aires, Tall. Gráf. Ferrari, 1929. 
Baldrich, Amadeo J.: Historia de la Guerra del Brasil. Buenos Aires, EUDEBA, 1975.

Beverina, Juan: La Guerra contra el Imperio del Brasil. Buenos Aires, 1927.

Brasiliano, Rúbio: O Rio Grande do Sul e a Cisplatina. Porto Alegre, Globo, 1935.

Calmón, Pedro: "Visao global da Batalha do Passo do Rosário". Revista do Instituto Histórico e Geográfico Brasileiro, vol. 318. Rio de Janeiro, enero-marzo, 1978.

Carneiro, David: História da Guerra Cisplatina. Sao Paulo, Ed. nacional, 1946.

Correa Luna, Carlos: La campaña del Brasil y la batalla de Ituzaingó. Buenos Aires, Instituto Geográfico Militar, 1927.

Cruz, Alcides de Freitas: Epítome da guerra entre o Brasil e as Provincias Unidas do Rio da Prata. Porto Alegre, Livraria do Comercio, 1907.

Fitte, Ernesto J.: Dorrego y Rosas. Entretelones del soborno de tropas mercenarias al servicio del Brasil. Buenos Aires, Fernández Blanco, 1961.

Heredia, Edmundo A.: "La diplomacia Brasileña ante la cuestión de la Banda Oriental". Revista-Libro Historia, año II, n. ${ }^{\circ}$ 6. Buenos Aires, julio-agosto, 1982.

Herrera, Luis Alberto de: La misión Ponsonby. La diplomacia británica y la independencia del Uruguay. Buenos Aires, EUDEBA, 1974.

Homen, Joaquin de Sales Torres: Annaes das guerras do Brasil com os Estados de Prata e Paraguay. Rio de Janeiro, Imprenta Nacional, 1911.

Mello, Arnaldo Vieira de: "Bolívar, o Brasil e os nossos vizinhos do Prata" (Da questao de Chiquitos á guerra da Cisplatina). Rio de Janeiro, Gráfica Olímpica Ed., 1963.

Pavón Pereyra, Enrique: "Bolívar, Dorrego, San Martín y la 'idea estratégica' en la primera guerra con el Brasil". Revista del Instituto de Investigaciones Históricas Juan Manuel de Rosas, n. ${ }^{\circ} 22$. Buenos Aires, julio-diciembre de 1960.

Pivel Devoto, Juan: "La misión de Nicolás Herrera a Río de Janeiro (18291830)". Revista del Instituto Histórico y Geográfico del Uruguay, vol. 8. Montevideo, 1932. 
Tjarks, Germán O.E.: "Dorrego y la guerra con el Brasil". Boletín de la Academia Nacional de la Historia, tomo XXXVI, 2. a sección. Buenos Aires, 1964.

- "Juan Florencio Perea, un agente del Imperio del Brasil en el Litoral Argentino". Cuarto Congreso Internacional de Historia de América, tomo VI. Buenos Aires, 1966.

Vázquez-Machicado, Humberto: "La invasión Brasilera de Chiquitos y la diplomacia Argentina de 1825". Segundo Congreso Internacional de Historia de América. Buenos Aires, 1938.

Vidaurreta de Tarjks, Alicia: "La independencia del Brasil y el Río de la Plata". Cuarto Congreso Internacional de Historia de América, tomo VII. Buenos Aires, Academia Nacional de la Historia, 1966.

Villegas Basavilbaso, Benjamín: "La adquisición de armamentos navales en Chile durante la Guerra del Brasil". Boletín del Instituto de Investigaciones Históricas, tomo VI. Buenos Aires, 1927.

\section{Rosas y el Imperio}

Acevedo, José R.S.: 1843: Caminhos e Descaminhos do Brasil no Prata. Brasília, Universidade de Brasília, 1981.

Brezzo, Liliana M.: "La misión diplomática de José Buschental a Brasil (1855)". Res Gesta, n. ${ }^{\circ} 23$. Rosario, enero-junio de 1988.

Calmon, Pedro: O Marqués de Abrantes. Rio de Janeiro, 1933.

Calogeras, Joao Pandiá: A política exterior do Império. Da Regencia á queda de Rosas. Sao Paulo, 1933.

Cervo, Amado L.: "Intervençao e neutralidade: Doutrinas brasileiras para o Prata nos meados do Séc. XIX". Revista Brasileira de Política Internacional, año 26, núms. 101/104. Rio de Janeiro.

Martínez, Pedro Santos: "Caseros, las tropas extranjeras y la política internacional rioplatense". Boletín de la Academia Nacional de la Historia, vol. XLVII (1974). Buenos Aires, 1975.

Quesada, Vicente G.: "La alianza contra Rosas y Oribe. El Brasil, Montevideo y las Provincias de Entre Ríos y Corrientes". Nueva Revista de Buenos Aires, tomo III. Buenos Aires, 1881.

Ramírez Juárez, Evaristo: Misión diplomática del General Guido al Brasil y el Tratado de 1843. Buenos Aires, 1938. 
Ribeiro, Duarte da Ponte: As relaçoes do Brasil com as repúblicas do Rio da Prata de 1829 á 1843. Rio de Janeiro, Arquivo Nacional, 1936.

Siegrist de Gentile, Nora: "Misión diplomática de Manuel de Sarratea al Brasil. 1838-1841. Su relación con la 'Liga Americana"”. América, año 1, núms. 2-3. Buenos Aires, agosto-diciembre de 1976.

Souza, José A. Soares de: "O General Urquiza e o Brasil". Revista do Instituto Histórico e Geográfico Brasileiro, vol. 206. Rio de Janeiro, enero-marzo de 1950.

- Honorio Hermeto no Rio da Prata (Missao Especial de 1851-1852). Sao Paulo, Cía. Editora Nacional, 1959.

- "O Brasil e o Rio da Prata, de 1828 á queda de Rosas". História Geral da Civilizaçao Brasileira, dir. Sergio Buarque de Holanda, vol. II, tomo 3. Sao Paulo, Dífusso Europea do Lívro, S. A.

\section{De la caída de Rosas a la Guerra del Paraguay}

Brezzo, Liliana M.: "La misión diplomática de José Buschental a Brasil (1855)". Res Gesta, n. ${ }^{\circ}$ 23. Rosario, enero-junio de 1988.

Cárcano, Ramón J.: "Los Tratados del Paraná. Derqui y Paranhos. 18561858". Revista de la Universidad Nacional de Córdoba, año V, n. ${ }^{\circ} 6$. Córdoba, diciembre de 1918.

- "La política internacional en el Plata durante el gobierno de la Confederación. Tratados y Alianzas (1855-1859)". Historia de la Nación Argentina, vol. VIII. Academia Nacional de la Historia. Buenos Aires, 1962.

\section{Desde la Triple Alianza hasta fines del XIX}

Abente Brun, Diego: "The War of the Triple Alliance: Explanatory Models". Latin American Research Review, n. ${ }^{\circ} 2$. Albuquerque, New Mexico, 1987. Versión portuguesa: "A Guerra da Tríplice Alianza: Tres modelos explanatórios". A Defesa Nacional. Rio de Janeiro, noviembre-diciembre de 1988. Versión castellana: "La Guerra de la Triple Alianza: Tres modelos explanatorios". Revista Paraguaya de Sociología. Asunción, enero-abril de 1989. 
Acuña, Angel: Antecedentes de la Guerra del Paraguay. Buenos Aires, 1930.

Alonso Piñeiro, Armando: La misión diplomática de Mitre en Río de Janeiro. 1872. Buenos Aires, Institución Mitre, 1972.

Amarilla Fretes, Eduardo: La liquidación de la Guerra de la Triple Alianza contra el Paraguay (negociaciones diplomáticas). Asunción, Imprenta Militar, 1941.

Besouchet, Lidia: Rio Branco e as relaçoes entre o Brasil e a República Argentina. Rio de Janeiro, Depto. Imprenta Nacional, 1949.

Bidabehere, Fernando Arturo: Mitre Diplomático. Buenos Aires, 1967.

Bormann, José B.: História da Guerra de Paraguai. Curitiba, Jesuíno Lopes e Cía, 1897.

Box, Pelham Horton: Los orígenes de la Guerra de la Triple Alianza. Buenos Aires, Ed. Nizza, 1958.

Brancato, Sandra M.: "As relaçoes Brasil-Argentina no ano de 1937: rivalidade e conflito". Estudos Ibero-Americanos. Porto Alegre, diciembre de 1988.

Burns, E. Bradford: "Rio Branco e a sua política externa". Revista de História, n. ${ }^{\circ}$ 58. Sao Paulo, abril-junio de 1958.

Calmón, Pedro: "Mitre y el Brasil". Mitre. Homenaje de la Academia Nacional de la Historia. Buenos Aires, 1957.

Cárcano, Ramón J.: "La misión Mitre en el Brasil (abril-diciembre de 1872)". Anales de la Facultad de Derecho y Ciencias Sociales, tomo II, 1. ${ }^{\text {a }}$ parte (2. ${ }^{\mathrm{a}}$ serie). Buenos Aires, 1913.

- "Política exterior argentina. Modificación de los Tratados de Lamas, de la Peña, Carneiro Leao y Florentino Castellanos (1852)". Anales de la Facultad de Derecho y Ciencias Sociales, tomo XX. Buenos Aires, 1919.

- Guerra del Paraguay. Orígenes y causas. Buenos Aires, Viau, 1939.

- Guerra del Paraguay. Acción y reacción de la Triple Alianza. Buenos Aires, 1941.

Cardozo, Efraín: Vísperas de la Guerra del Paraguay. Buenos Aires, El Ateneo, 1954.

- Crónica de la Guerra de 1864-1870. Hace cien años. Asunción, 19671970.

Correia, Manoel Francisco: "Missao especial do General Argentino D.Bartolomé Mitre ao Brazil em 1872 (negociaçao confidencial)". 
Revista Trimestral do Instituto Histórico e Geográfico do Brasil, tomo LX, Parte I. Rio de Janeiro, 1897.

Chiavenatto, Julio José: Genocidio americano: A Guerra do Paraguai. Sao Paulo, Ed. Brasiliense, 1979.

Etchepareborda, Roberto: "Enfrentamiento argentino-brasileño al finalizar la Guerra del Paraguay: un episodio de espionaje en el Río de la Plata en 1874". Investigaciones y Ensayos, $\mathrm{n}^{\circ}{ }^{\circ} 10$. Academia Nacional de la Historia. Buenos Aires, enero-junio de 1971.

- "Las tensiones en el Plata vistas a través de la información diplomática (1907-1910)". Investigaciones y Ensayos, n. ${ }^{\circ}$ 17. Academia Nacional de la Historia. Buenos Aires, julio-diciembre de 1971.

Fragoso, Augusto Tasso: História da guerra entre a Tríplice Alianza e o Paraguay. Rio de Janeiro, 1943.

Herrera, Luis Alberto de: La culpa Mitrista (El drama del 65). Buenos Aires, Plus Ultra, 1965.

Licandro, Hugo: "La guerra del Paraguay (Sus orígenes y la lucha diplomática)". Cuadernos de Marcha, n. ${ }^{\circ}$ 5. Montevideo, septiembre de 1967.

Lobo, Eulalia M. Lahmeyer: "A importáncia estratégica e económica da provincia de Santa Cruz de la Sierra durante a Guerra da Tríplica Alianza”. Boletim de História. Centro de Estudos de História, n. ${ }^{\circ} 6$. Rio de Janeiro.

Lobo, Helio: Antes da guerra. A missao Saraiva u os preliminares do conflito com o Paraguai. Rio de Janeiro, 1914.

Madureira, A. de Sena: Guerra do Paraguay. Rio de Janeiro, Typ. di Imperial Instituto Artístico, 1870.

Nabuco, Joaquin: La guerra del Paraguay. París, Garnier Hnos., 1901.

Pomer, León: La guerra del Paraguay. Buenos Aires, Ed. Caldén, 1968.

Resquin, Francisco Isidoro: Datos históricos de la guerra del Paraguay contra la Triple Alianza. Asunción, Imprenta Militar, 1971.

Riquelme, Norma Dolores: "Notas referentes a las relaciones entre Argentina y Brasil durante los años 1880 a 1886". Anuario del Departamento de Historia, año II-III (1964-1965), n. ${ }^{\circ}$ 2, Universidad Nacional de Córdoba. Córdoba, 1968.

Schneider, Luis: A Guerra da Tríplice Alianza contra o Governo da República do Paraguay; 1864-1870. Sao Paulo, Ed. Cultura, 1945.

Soares, Alvaro Teixeira: O Drama da Tríplice Alianza (1865-1876). Rio de Janeiro, Brand, 1956. 
Sousa, F. de: Causas da Guerra com o Paraguay. Porto Alegre, 1919.

Thompson, George: Guerra do Paraguai. Rio de Janeiro, Ed. Conquista, 1968.

Versen, Max Von: História da Guerra do Paraguai. Belo Horizonte, Livraria Itatiaia, 1976.

Warren, Harris Gaylord: Paraguay and the Triple Alliance: The post-war decade, 1869-1878. Austin, Institute of Latin American Studies, 1978.

\section{Siglo XX}

Brancato, Sandra M.: "As Relaçoes Brasil-Argentina no ano de 1937: Rivalidade e Conflito". Estudos Ibero-Americanos. Porto Alegre, 1988.

Etchepareborda, Roberto: "Las tensiones en el Plata vistas a través de la información diplomática (1907-1910)". Investigaciones y Ensayos, n. ${ }^{\circ}$ 17. Buenos Aires, 1974.

Hirst, Mónica: "Vargas y Perón. Las relaciones argentino-brasileñas". Todo es Historia, n. ${ }^{\circ} 224$. Buenos Aires, 1985.

Paiva Abreu, Marcelo de: "La Argentina y Brasil en los años 30. Efectos de la política económica internacional Británica y Estadounidense". Desarrollo Económico, n. ${ }^{\circ}$ 96, vol. 24. Buenos Aires, 1985.

Zeballos, Estanislao: Diplomacia Desarmada. Buenos Aires, 1910.

\section{Economía}

Barreto, Antonio E. Muniz: Evoluçao histórica do Comercio Argentinobrasileiro (1800-1930). Tesis doctoral. Faculdade de Ciencias Económicas e Administrativas da Universidade de Sao Paulo. Sao Paulo, 1972.

- "O Fluxo de Moedas entre o Rio da Prata e o Brasil (1800-1850)". Revista de História, n. ${ }^{\circ}$ 101. Sao Paulo, enero-marzo de 1975.

Canabrava, Alice Piffer: "O Comercio Portugués no Rio da Prata. 15801640". Boletim História da Civilizaçao Americana, XXXV, n. ${ }^{\circ} 2$. Universidade de Sao Paulo, 1944. 
Malgesini, Graciela N. y Gabriela M. Coconi: "Trigo versus erva-mate: O intercambio Argentina-Brasil e a questao regional de misiones (19201945)". Estudos Económicos. Sao Paulo, mayo-agosto de 1986.

Paiva Abreu, Marcelo de: "La Argentina y Brasil en los años 30. Efectos de la política económica internacional Británica y Estadounidense". Desarrollo Económico, n. ${ }^{\circ}$ 96, vol. 24. Buenos Aires, enero-marzo de 1985.

Rand, Frances Elizabeth: "O banqueiro brasileiro Mauá - Dois de seus sócios e as Guerras do Rio da Prata, 1863-1866". Revista do Instituto Histórico e Geográfico Brasileiro, vol. 318. Rio de Janeiro, eneromarzo de 1978.

Santos, Corcino Medeiros dos: "El tráfico de esclavos entre el Brasil y el Río de la Plata". Res Gesta, n. ${ }^{\circ}$ 8. Rosario, julio-diciembre de 1980.

- "Mauá e a influencia brasileira no Rio da Prata". Revista de Historia de América. México, julio-diciembre de 1987.

Soares, Alvaro Teixeira: O gigante e o Rio (Açao de Mauá no Uruguai e Argentina). (1851-1878). Rio de Janeiro, Cía. Brasileira de Artes Gráficas, 1957.

\section{Fronteras y límites}

Aguilar y Jurado, Vicente y Francisco Requena: Historia de la demarcación de límites en la América entre los dominios de España y Portugal... con arreglo al Tratado Preliminar de Límites de 1777. Montevideo, Imprenta del Comercio del Plata, 1846.

Almeida, Luis Ferrand de: A Diplomacia Portuguesa e os limites meridionais do Brasil. Coimbra, 1957.

Alonso Piñeiro, Armando: "El eterno conflicto argentino-brasileño". Separata de la Revista Redacción, mayo de 1974.

Ferreira Reis, Arthur R.: As fronteiras com as colonias espanholas. Rio de Janeiro, 1948.

Lobo, Helio: Rio Branco e o arbitramento com a Argentina. A questao do Território de Palmas tambem chamado das Missoes. Rio de Janeiro, 1952.

Magalhaes, Basílio de: Expansao Geográfica do Brasil Colonial. Sao Paulo, 1935. 
Nobre, Fernando: As fronteiras do Sul. Sao Paulo, Monteiro, Locato y Cía, 1922.

Quesada, Vicente G.: La política imperialista del Brasil y las cuestiones de límites de las Repúblicas Sudamericanas. Buenos Aires, Vaccaro, 1920.

Sánchez, Zacarías: La frontera Argentino-Brasileña. Buenos Aires, 1910.

Sanz, Luis Santiago: La cuestión de Misiones. Ensayo de su historia diplomática. Buenos Aires, Libr. Ed. Ciencias Económicas, 1957.

Siegrist de Gentile, Nora: "Antecedentes históricos de la evolución fronteriza Argentino-brasileña y sus relaciones y consecuencias con las del Uruguay, Paraguay y Bolivia". América, año IV, n. ${ }^{\circ} 10$. Buenos Aires, abril de 1979.

- "Fronteras exteriores Argentino-brasileño-uruguayas (1828-1851)". Nuestra Historia, año XVII, n. ${ }^{\circ} 33-34$. Buenos Aires, diciembre de 1984.

Soares, Alvaro Teixeira: História da formaçao das fronteiras do Brasil. Rio de Janeiro, Cons. Fed. de Cultura, 1972.

Vianna, Helio: História das fronteiras do Brasil. Rio de Janeiro, 1949. 